\title{
The Altruism Framework, Bystander Effect and A-Rules: A New Perspective
}

\author{
Shagnik Saha \\ Research Assistant, Centre for Health Policy, Asian Development Research Institute, Patna, Bihar.
}

Corresponding author: Shagnik Saha

Email-shagniksaha.ss@gmail.com

\begin{abstract}
This paper reviews the Bystander Effect, and its componential phenomena, namely, Diffusion of Responsibility, Pluralistic Ignorance, Deindividuation, Self-Categorization Theory, Group Size, Group Cohesiveness, Self-Efficacy, Ringelmann Effect, Social Exchange Theory, and Altruism. The aim of the analysis presented in this paper is to, propose a hypothetical framework, called "The Altruism Framework" that maps the decision-making process leading up to not only the Bystander Effect but other related phenomena such as the Martyrdom Effect and various forms of Altruism bringing everything together into one Helping Behavior Framework. An additional concept of A-rules, is also introduced to further consolidate the framework.
\end{abstract}

Keywords: Bystander effect, Altruism, Cognitive.

(Paper received $-24^{\text {th }}$ February 2018, Peer review completed $-2^{\text {nd }}$ April 2018)

(Accepted $-22^{\text {nd }}$ April 2018)

\section{INTRODUCTION}

The Bystander Effect was spawned as a result of the murder of Catherine 'Kitty' Genovese in 1964 [1] (Gansberg, 1964), wherein 38 neighbours were present at the time of the crime who heard the crime taking place and also the screams of the victim, begging for help but no one intervened. This led to the milestone research of John Darley and Bibb Latané, called the The Bystander Apathy Experiment [2]. They attributed the presence of the Bystander Effect to two factors: Diffusion of Responsibility and Pluralistic Ignorance [2].

Diffusion of Responsibility implies that the individuals don't intervene and initiate helping behaviour in case of emergency because they believe and expect that the others present will administer the required assistance [2-4] irrespective of the situation being an emergency in nature or not [5]. An interesting example of this was seen in the Tipping Experiment wherein the tip size was an inverse function of the number of people eating at the restaurant [6]. In fact, research has found evidence of the capability of the Diffusion of Responsibility not only to counteract the effects of the Escalation Tendency in High-Risk environments [7], but also decrease response rates in e-mails when it is addressed to more number of individuals [8]. Pluralistic Ignorance refers to an individual deciding to not intervene and initiate helping behaviour because others present are not doing anything either [2, 9-10].

One would be able to see how both of them feed into each other in an endless vicious cycle. Because of the Diffusion of Responsibility an individual $\mathrm{Z}$ would refrain from taking a step towards helping an individual $\mathrm{Y}$ in need assuming that one of the the others present, say $\mathrm{P}, \mathrm{Q}, \mathrm{R}, \mathrm{S}$ and $\mathrm{T}$, would intervene. However, simultaneously, the individuals $\mathrm{P}, \mathrm{Q}, \mathrm{R}, \mathrm{S}$ and $\mathrm{T}$ are also, theoretically, thinking the same thing, therefore no one amongst them, also, decides to intervene assuming and expecting that the others will. At this point, 
no one amongst the individuals present is taking the initiative, including $\mathrm{P}, \mathrm{Q}, \mathrm{R}, \mathrm{S}, \mathrm{T}$ and $\mathrm{Z}$. This is where the Pluralistic Ignorance aspect comes into play. Since, no one is intervening, it now becomes all the more difficult for an individual to be the odd one out, and actually intervene, because of various reasons that could range around conformity and a fear of being ostracised later, for breaking the invisiblemisinterpreted-rule, or an a-rule. This paper would like to define an a-rule as a distorted cognitive assumption based on misinterpretation, or in simpler words, a rule, that is not really a rule. In this case, this misinterpreted rule would be, "We are not supposed to intervene."

It is now understood that during the bystander effect, there is also an aspect of Deindividuation that comes into place, or a certain anonymity, wherein an individual lose their sense of self and instead assume the collective identity of the larger group [11-12] which allows actions that would otherwise not be initiated or condoned, to go on. This deindividuation is also what forms the basis of riots and mobs, as it allows the individual to be known by the identity of the group and it becomes almost natural to uphold any and all actions to preserve not only the sanctity and purpose of the group but also conform to the norms of that group [13-14]. Now, one would be able to see how it would be so necessary and important to conform to the a-rule being seen as a norm in that situation with respect to the group present, but which in reality is merely a cognitive distortion.

Since that time, a lot of new perspectives have come up. Over time people have realised that a lot of variables are consequential in the culmination of the bystander effect. But at the same time, the Bystander Effect has proven to be extremely resilient and consistent across cultures, setting and other factors [15-16]. The aim of this paper is to formulate a model that describes the componential framework consisting of all variables and logical combinations that lead to an individual showing bystander effect.

One of the factors that greatly impacts the bystander effect is whether there are similarities between the helping individual and the victim such as shared interests, leading to a reduction in bystander effect [17]. This reduction can be explained when one takes into consideration, the concept of deindividuation mentioned above. According to Self-Categorization Theory [18-19], the self goes through levels of abstraction ranging from the personal self ("I") to the collective self ("We"). However, it must be noted that these are not the only levels of abstractions, as there can be an endless number of levels may go through and combinations that the self may take while going through a day. These interests can be as simple in nature as liking for the same football team, or as far reaching and complex as religion. One can understand how a similar interest being shared would be seen as an instantaneous in-group formation and therefore the individual would then be expected to follow the unsaid norms of this in-group. For instance, an individual $\mathrm{B}$ is in need of help, and there is an out-group composed of five individuals, who also happen to be bike enthusiasts. According to what we now know, if these individuals are suddenly made aware of the possibility of B being a "motorist" the bystander effect would decline, however, after that if they are made aware that B is primarily a car enthusiast, the helping behaviour again declines [17]. But at the same time, it must also be noted that, since there is an instantaneous in-group formation, the norms of that ingroup might also motivate the helping individual to not intervene. For instance, if the in-group consists of individuals who believe that suicide is an honourable act and it is up to an individual to choose whether to take their own life or not, then it is unlikely that the spike in helping behaviour would be seen or be considered to be helping in the traditional way.

The other important factor is the group size of the out-group, with there being a significant negative correlation between group size and helping behaviour such that, as group size increases, helping behaviour decreases. This particular aspect gives a lot of back-confirmation to the original idea of Pluralistic Ignorance by Latané and Darley [2], as larger the group, larger would be the expectation on the individual to conform. At the same time, there is evidence that increasing group size can also increase or decrease helping behaviour by interacting with context dependent factors, such as extremely high group cohesiveness, or the presence of a strong social category [20].

Another factor that effects the bystander effect is whether the helping individual and the victim share a social category membership, with helping behaviour increasing with the significance of the social group that is in question [21]. This understanding is further corroborated with what we know of the Self Categorisation Theory [19]. What this means to say is that there is a higher probability of a female helping individual actually helping a female victim than a male victim, or an individual from a specific cultural 
community willing to be more helpful if the other individual is from their community as well. However, there is also a combination effect when gender identity is made salient with helping behaviour increasing for a female victim, with female onlookers, when the group size is increased, but the same has not been observed for males [20].

Talking about social groups, another factor that makes a significant impact on the expression of Bystander Effect is the extent of Group Cohesiveness. In a breakthrough study by Rutkowski and others [22], it was found that the more cohesive a group is, the more likely it is that helping behaviour would be demonstrated by the members of that group, but it is also important to note that is only the case, when a social-responsibility norm is made salient beforehand. This can also be seen to be quite synchronous with what the paper proposes about instantaneous in-group formations, as discussed above. Another observation was that, high group cohesiveness can also decrease bystander effect, possibly because it somewhat reduces Pluralistic Ignorance, and the prevalence of the a-rule, because an individual is less likely to feel the fear of a possible ostracization later on because he/ she has done something the group doesn't agree to, on one occasion [23].

Another very significant aspect that modulates the Bystander Effect is how capable the individual feels, about being able to administer the help required in a certain situation [9]. For instance, while walking on the road the individual witnesses a gruesome accident. The victim is still alive but is bleeding heavily. Therefore, in this situation what is needed is for someone to help the victim by reducing the blood flow by some first aid measure. However, if the helping individual is not aware of any such measures in the first place, then it is unlikely that any helping behaviour will be shown $[9,24]$. The impact of self-efficacy in bullying has also been seen to the extent that self-efficacy is positively correlated with the decision to intervene, meaning someone with a high defender self-efficacy is more likely to intervene when other parameters are kept constant [25]. However, that being said, it must be noted that with increase in group size, the individual self-efficacy levels consistently decline [26].

At this point, it is important that the Ringelmann Effect [27-29] be discussed as well, which essentially states that the addition of coworkers in a task leads to a linear decrement in the performance levels, per individual. This effect is also referred to as Social Loafing [30-31]. However, according to a recent study, where coworkers were added one by one, it was seen that the performance per individual dropped significantly up till the addition of two, three, and four people, but the decrements in performance on the addition of the fifth and sixth coworkers, was negligible, thereby telling us that that relationship is not linear, but curvilinear [32]. This is significant because it tells us that as other individuals are added in the equation, the amount of responsibility on one individual also decreases, finally reaching an equilibrium, wherein the individual is no longer underperforming or over-performing.

However, this is all the more meaningful because it tells us how the individual processes and balances the concepts of cost to self, performance required, and the profit to self. The Social Exchange Theory suggests that altruistic behaviour, or true helping behaviour, takes place only when the costs to the self, outweighs the profits to the self [33]. But another way of looking at it is that when an individual has the sole responsibility of performing, the performance is much higher than their equilibrium level, because they are responsible for the entire weight of the outcome, therefore, an individual is ready to perform at a higher level, which can be considered a higher cost to self, because the profit at the end of the process, could be something like respect from his/ her peers, avoiding embarrassment, or a sense of fulfilment of having done something more-than-ordinary, thereby drawing solace and satisfaction from cultural ideas of sacrifice, also called, the Martyrdom Effect [34]. According to Batson [35-36], there are four basic types of altruism: ultimately benefitting the self (egosim), ultimately benefitting the other (altruism), ultimately benefitting a group (collectivism), for upholding a principle (principalism), therefore in cases one, three and four, it is essentially the self that is benefitted, either directly or indirectly [37-38] and it is only the second case where one can say that selfless altruism has taken place [39-40]. To a large extent the Social Exchange Theory and the Martyrdom Effect can be seen as being in harmony, once we take an indirect perspective to Bystander Effect and Helping. At this point, this paper would like to propose the concept of the Cost Calculator, as a meta-structure in the cognitive model which functions as the final weighing scale, and its functioning is explained later. The following model attempts to delineate all of these factors into a comprehensive model. 


\section{DISCUSSION}

The current model which houses the Bystander Effect is composed of various sub-factors that ultimately feed into whether a helping behaviour occurs or not. When an individual is presented with a situation where such a decision needs to be taken, all these sub-factors are activated simultaneously, so the individual starts analysing all these variables in that particular situation, i.e., what is the group size like, can I defy the people present here, how close am I to this group, what is my relationship to the individual in need of help, what are the unsaid norms currently in play, would I be able to successfully help this individual even if I decided to, what do I get if I help the individual, and so on and so forth. Once the processing of the sub-factor or the variable is initiated, it yields a positive or a negative response for that particular sub-factor. It can be said, that the individual enters into a dialogue with himself or herself, with respect to his/ her sub-factors. For instance, an individual who is strongly cohesive to the group and shares similarities to the victims, might get positive responses for those two sub-factors but a strongly negative score for self-efficacy. Needless to say, the responses are most likely to be along a dimension of Very Negative to Very Positive, with every possible combination in between, and not in a yes/ no manner. Once the responses for each sub-factor are generated, they are then sent to the Cost Calculator, which is essentially as the name suggests, a calculator whose primary function is to generate a cumulative score by addition of the sub-factor responses.

Once the final response is generated by the Cost Calculator, the individual proceeds to act in the way that is synergistic with the decision making process that has just taken place. Thus, one would be able to see how the Bystander Effect is truly an effect of various considerations, that have together been termed as the Altruism Framework by this paper, which is the bigger decision-making process that an individual engages in during helping behaviour and wherein, the Bystander Effect is only one of the results of this Framework's functioning. For instance, taking a hypothetical example, an individual is presented with a scenario wherein he/ she sees another individual getting mugged on the street. The people present there are only the perpetrator, the victim and the individual we are interested in observing. Instantaneously, the individual starts evaluating the situation in terms of all the possible parameters.

In this current example, Group Cohesiveness, Pluralistic Ignorance and Diffusion of Responsibility are unlikely to play a role. The aspect of Similarities and Social Categories, if they happen to become known or are made salient in some manner, then it is likely that they would play a role. However, assuming the case that none of these factors are playing a major role, the primary input to the Cost Calculator is from the Ethical Code that an individual holds, which therefore explains the highly documented absence of the Bystander Effect when the individual is alone with the victim in a certain scenario. Needless to say, in this case, the aspect of Ethical Code may go in both directions, positive and negative, or prosocial and antisocial (see figure below).

\section{IMPLICATIONS FOR RESEARCH}

The paper implicates the need for a complete overhaul on the outlook and understanding we have on not only the Bystander Effect but also of Altruism as a whole, seeing Bystander Effect or Altruistic actions as merely end products of a larger and much more complicated decision-making process that all individuals engage in. This would as a result impact everything from Donation drives, to interpersonal dynamics in terms of group-goal participation and compromise of personal viewpoints.

\section{REFERENCES}

1. Gansberg M. Thirty-eight who saw murder didn't call the police. New York Times 1964;Mar 27:27.

2. Darley JM, Latané B. Bystander intervention in emergencies: diffusion of responsibility. J Personal Soc Psychol 1968;8(4):377-89.

3. Schwartz SH, Gottlieb A. Bystander reactions to a violent theft: Crime in Jerusalem. J Personal Socl Psychol 1976;34(6):1188-95.

4. Guerin B. Diffusion of responsibility. Blackwell Publishing Ltd: London; 2011.

5. Bickman L. Social influence and diffusion of responsibility in an emergency. J Experiment Soc Psychol 1972;8(5):438-45. 


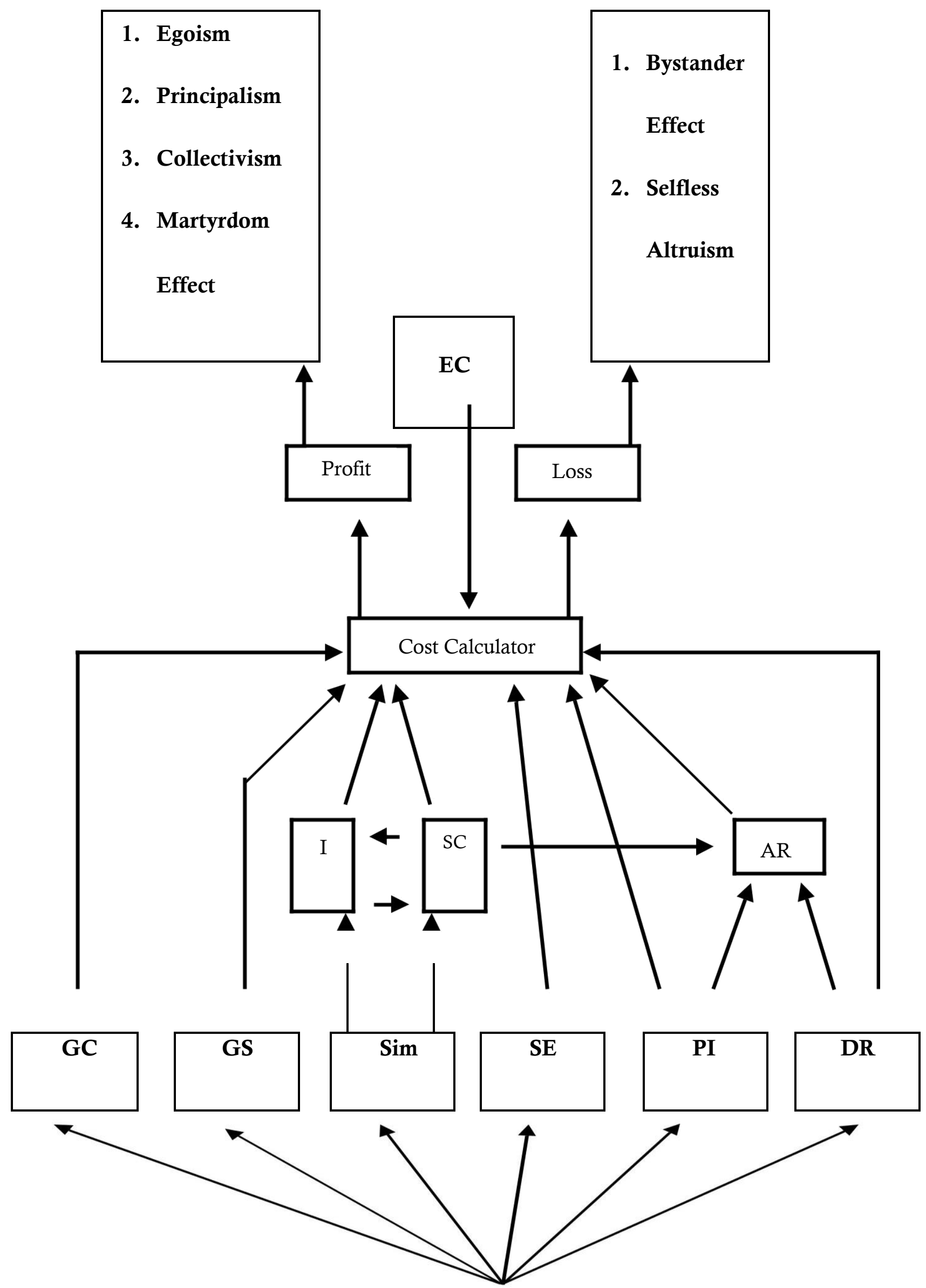


GC: Group Cohesiveness, GS: Group Size, Sim: Similarities, I: Interests, SC: Social Category, SE: Self Efficacy, AR: A- Rule, PI: Pluralistic Ignorance, DR: Diffusion of Responsibility, EC: Ethical Code

\section{REFERENCES (Continued)}

6. Freeman S, Walker MR, Borden R, Latane B. Diffusion of responsibility and restaurant tipping: Cheaper by the bunch. Personal Soc Psychol Bull 1975;1(4):584-7.

7. Whyte G. Diffusion of responsibility: Effects on the escalation tendency. J Appl Psychol 1991;76(3):408-15.

8. Barron G, Yechiam E. Private e-mail requests and the diffusion of responsibility 谉. Comp Hum Behav 2002;18(5):507-20.

9. Aronson E, Wilson T, Akert R. Social Psychology (8th ed.). Upper Saddle, New Jersey:Pearson Education Inc; 2013.

10. Miller DT, McFarland C. Pluralistic ignorance: When similarity is interpreted as dissimilarity. J Personal Soc Psychol 1987;53(2):298-308.

11. Diener E. Deindividuation: The absence of self-awareness and self-regulation in group members. Psychology of Group Influence 1980;209242.

12. Reicher SD, Spears R, Postmes T. A social identity model of deindividuation phenomena. Eur Rev Soc Psychol 1995;6(1):161-98.

13. Zimbardo PG. The human choice: Individuation, reason, and order versus deindividuation, impulse, and chaos. In Nebraska symposium on motivation. University of Nebraska Press; 1969.

14. Bandura A, Underwood B, Fromson ME. Disinhibition of aggression through diffusion of responsibility and dehumanization of victims. J Res Personality 1975;9(4):253-69.

15. Latané B, Nida S. Ten years of research on group size and helping. Psychol Bull 1981;89(2):308-20.

16. Fischer P, Krueger JI, Greitemeyer T, Vogrincic C, Kastenmüller A, Frey D, Heene M, Wicher M, Kainbacher M. The bystander-effect: A meta-analytic review on bystander intervention in dangerous and non-dangerous emergencies. Psychol Bull 2011;137(4):517-26.

17. Levine M, Prosser A, Evans D, Reicher S. Identity and emergency intervention: How social group membership and inclusiveness of group boundaries shape helping behavior. Personal Soc Psychol Bull 2005;31(4):443-53.

18. Turner JC. Social categorization and the self-concept: A social cognitive theory of group behavior. Adv Group Processes 1985;2:77-122.

19. Turner JC, Hogg MA, Oakes PJ, Reicher SD, Wetherell MS. Rediscovering the social group: A selfcategorization theory. Basil Blackwell: UK; 1987.

20. Levine M, Crowther S. The responsive bystander: How social group membership and group size can encourage as well as inhibit bystander intervention. J Personal Soc Psychol 2008;95(6):1429-36.

21. Batson CD, Sager K, Garst E, Kang M, Rubchinsky K, Dawson K. Is empathy-induced helping due to selfother merging? J Personal Soc Psychol 1997;73(3):495-503.

22. Rutkowski GK, Gruder CL, Romer D. Group cohesiveness, social norms, and bystander intervention. J Personal Soc Psychol 1983;44(3):545-51.

23. Manning R, Levine M, Collins A. The Kitty Genovese murder and the social psychology of helping: The parable of the 38 witnesses. Amer Psychologist 2007;62(6):555-70.

24. Langhinrichsen-Rohling J, Foubert JD, Brasfield HM, Hill B, Shelley-Tremblay S. The men's program: Does it impact college men's self-reported bystander efficacy and willingness to intervene?. Violence Against Women 2011;17(6):743-59.

25. Thornberg R, Jungert T. Bystander behavior in bullying situations: Basic moral sensitivity, moral disengagement and defender self-efficacy. J Adolescence 2013;36(3):475-83.

26. Kerr NL. Illusions of efficacy: The effects of group size on perceived efficacy in social dilemmas. J Experiment Soc Psychol 1989;25(4):287-313.

27. Ringelmann M. Research on animate sources of power: The work of man. InAnnales de l'Institut National Agronomique 1913 (Vol. 12, No. 2, pp. 1-40).

28. Witte EH. Köhler rediscovered: The anti- Ringelmann effect. Eur J Soc Psychol 1989;19(2):147-54.

29. Harkins SG. Social loafing and social facilitation. J Experiment Soc Psychol 1987;23(1):1-8.

30. Karau SJ, Williams KD. Social loafing: A meta-analytic review and theoretical integration. J Personal Soc Psychol 1993;65(4):681-9.

31. Latané B, Williams K, Harkins S. Many hands make light the work: The causes and consequences of social loafing. J Personal Soc Psychol 1979;37(6):822-30. 
32. Ingham AG, Levinger G, Graves J, Peckham V. The Ringelmann effect: Studies of group size and group performance. J Experiment Soc Psychol 1974;10(4):371-84.

33. Maner JK, Luce CL, Neuberg SL, Cialdini RB, Brown S, Sagarin BJ. The effects of perspective taking on motivations for helping: Still no evidence for altruism. Personal Soc Psychol Bull 2002;28(11):1601-10.

34. Olivola CY, Shafir E. The Martyrdom Effect: When pain and effort increase prosocial contributions. J Behav Decision Making 2013;26(1):91-105.

35. Batson CD, Van Lange PA, Ahmad N, Lishner DA. Altruism and helping behavior. The Sage Handbook of Social Psychology 2003;1:279-95.

36. Batson CD, Fultz J, Schoenrade PA, Paduano A. Critical self-reflection and self-perceived altruism: When self-reward fails. J Personal Soc Psychol 1987;53(3):594-9.Andreoni J. Impure altruism and donations to public goods: A theory of warm-glow giving. The Economic J 1990;100(401):464-77.

37. Andreoni J. Impure altruism and donations to public goods: A theory of warm-glow giving. The Economic J 1990;100(401):464-77.

38. Andreoni J. Giving with impure altruism: Applications to charity and Ricardian equivalence. J Political Econ 1989;97(6):1447-58.

39. Trivers RL. The evolution of reciprocal altruism. Quarterly Review of Biology 1971;46(1):35-57.

40. Nagel T. The possibility of altruism. Princeton University Press: USA; 1978

$* * * * * * * * * * * * * * * * * * * * * * * * * * * * * * * * * *$

Acknowledgements - Nil

Conflict of Interest - Nil

Funding - Nil 